\title{
Penyebab Unmet Need KB Dari Sudut Pandang Budaya Minangkabau di Nagari Lambah Kecamatan Ampek Angkek Kabupaten Agam
}

\author{
Fahrunnisa ${ }^{1}$, Agus Meilinda ${ }^{2}$ \\ ${ }^{1}$ RS Harapan Bunda Batam, Indonesia \\ 2 Poltekkes Kemenkes Padang, Indonesia
}

Informasi Artikel:

Diterima: Mei, 2015

Disetujui: Oktober, 2015

${ }^{*}$ Korespondensi penulis. meilindaagus@yahoo.com

\begin{abstract}
ABSTRAK
Unmet need $\mathrm{KB}$ adalah wanita yang membutuhkan $\mathrm{KB}$ tetapi tidak terpenuhi. Salah satu sasaran program BKKBN 2010-2014 adalah menurunnya angka unmet need dari 9,1\% menjadi $5 \%$ dari jumlah PUS. Penelitian ini ingin mengetahui faktor penyebab unmet need KB dari sudut pandang Budaya Minangkabau di Nagari Lambah Kecamatan Ampek Angkek Kabupaten Agam.
\end{abstract}

Penelitian ini merupakan penelitian kualitatif dengan informan PUS di Nagari Lambah dengan pengambilan sampel yang menggunakan teknik Quota Sampling. Pengumpulan data dilakukan secara in-depth interview kepada PUS dan 4 orang tokoh masyarakat, yaitu: Niniak Mamak, Alim Ulama, Cadiak Pandai, dan Bundo Kanduang.

Hasil penelitian menunjukkan bahwa penyebab unmet need $\mathrm{KB}$ adalah adanya larangan suami, keinginan terhadap jenis kelamin anak tertentu, dan rumor dan mitos yang negatif terhadap KB. Budaya ini juga berkaitan dengan matrilineal dan harato pusako di Minangkabau. Selain nilai budaya, nilai agama juga ikut mempengaruhi.

Kata kunci: Keluarga berencana, Minangkabau, Nilai agama, unmet need

\begin{abstract}
Unmet need for family planning $(F P)$ is women that cannot meet their need of contraceptives. Factors to cause unmet need of contreaceptives seen from Minangkabau culture in Nagari Lambah of Ampek Angkek Sub-district of Agam District in 2014 was not yet known.
\end{abstract}

This was a qualitative research. The informants were all couples of reproductive age (PUS) in Nagari Lambah with quote sampling. Data was collected with in-depth interviews to PUS and 4 public figures, namely Niniak Mamak, Alim Ulama, Cadiak Pandai, and Bundo Kanduang.

The results showed that the causes of unmet need for FP were prohibition from husband, desire for certain gender of child, and negative myths and rumors about contraception. This culture was related to matriarch and Harato Pusako in Minangkabau. In addition to culture, religion also influenced respondents' unmet need of FP.

Key words: Family Planning, Minangkabau, Religion values, unmed need 


\section{PENDAHULUAN}

Unmet need $\mathrm{KB}$ adalah wanita yang membutuhkan KB tetapi tidak terpenuhi. Pasangan Usia Subur (PUS) bukan peserta $\mathrm{KB}$ yang ingin menunda memiliki anak selama 2 tahun atau lebih dan tidak ingin memiliki anak lagi merupakan sasaran pelayanan $\mathrm{KB}$ yang belum terlayani, atau disebut unmet need KB (BKKBN, 2013). Salah satu sasaran program BKKBN 2010-2014 adalah menurunnya kebutuhan ber-KB yang tidak terlayani (unmet need) dari 9,1\% (SDKI 2007) menjadi sekitar 5\% dari jumlah pasangan usia subur (BKKBN, 2013).

Indonesia merupakan salah satu negara yang terikat dengan komitmen Family Planning 2020, yaitu suatu program yang bertujuan untuk peningkatan sebanyak 120 juta wanita di negara termiskin di dunia untuk menggunakan kontrasepsi modern pada tahun 2020. Salah satu daerah di Indonesia yang masih memiliki angka unmeet need yang tinggi adalah Sumatera Barat. Sumatera Barat menduduki urutan ke-18 tertinggi yaitu $15,17 \%$ dan Ampek Angkek merupakan kecamatan di Kabupaten Agam di wilayah Sumatera Barat yang mempunyai angka unmet need $\mathrm{KB}$ ke-2 tertinggi (14,3\%), dari enam belas kecamatan yang ada (BKKBN, 2012).

Sumatera Barat dikenal dengan falsafah hidup "Adat Basandi Syara', Syara' Basandi Kitabullah", dan matrilineal yang masih menganut budaya 'banyak anak banyak rezeki'. Oleh karena itu, alasan penolakan dari pihak keluarga merupakan hambatan dalam ber-KB, seperti dari pihak suami, pihak orang tua atau mertua, maupun saudara. "Adat Basandi Syara', Syara' Basandi Kitabullah", adalah ciri khas adat Minangkabau yaitu masyarakat beradat dan beradab yang beragama Islam (Abidin, 2013)

Kecamatan Ampek Angkek memiliki angka unmet need KB tinggi (14,3\%), sedangkan Nagari Lambah memiliki angka unmet need 7\%. Nagari Lambah adalah salah satu dari 7 nagari yang terdapat di Kecamatan Ampek Angkek dengan populasi penduduk \pm 4.106 jiwa. Nagari Lambah pada pemerintahannya melibatkan berbagai komponen yang ada di masyarakat dengan pengaruh unsur adat dan agama yang tetap berperan serta dalam pengambilan keputusan, seperti peran alim ulama, ninik mamak, bundo kanduang, pemuda, dan komponen lainnya (Rahmi, dkk, 2013).

Penyebab terjadinya unmet need $\mathrm{KB}$ pada wanita dan pria yang telah menikah adalah keinginan untuk mempunyai anak sesuai keinginan, penentangan penggunaaan $\mathrm{KB}$, pelarangan oleh suami ataupun pasangan untuk penggunaan $\mathrm{KB}$, kurangnya pengetahuan tentang metode $\mathrm{KB}$, dan ketakutan terhadap efek samping metode alat kontrasepsi $\mathrm{KB}$ (Lee dan Cheng, 2012). Saat ini, penyebab unmet need KB di Nagari Lambah belum diketahui sehingga penelitian ini sangat penting untuk dilakukan untuk dapat mengambil langkah intervensi untuk mengatasi permasalahan tersebut.

\section{BAHAN DAN METODE}

Penelitian ini menggunakan metode penelitian kualitatif, yang bertujuan untuk mengidentifikasi secara mendalam faktor penyebab unmet need $\mathrm{KB}$ dari sudut pandang budaya Minangkabau di Nagari Lambah Kecamatan Ampek Angkek Kabupaten Agam.

Informan kunci dalam penelitian ini adalah PUS dengan unmet need KB di Nagari Lambah sebanyak 10 orang. Pengambilan informan kunci dilakukan dengan menanyakan informasi mengenai PUS dengan unmet need KB kepada kader Posyandu.

Informan pendukung dalam penelitian ini adalah empat tokoh masyarakat di Nagari Lambah, yaitu Alim Ulama, Cadiak Pandai, Niniak Mamak, Bundo Kanduang, PKK, dan kader Posyandu.

Analisis data dalam penelitian ini menggunakan reduksi data, penarikan kesimpulan, dan verifikasi. Kesimpulan senantiasa dilakukan selama penelitian berlangsung. Verifikasi dapat dilakukan secara singkat dengan mencari data baru. Analisis dituangkan dalam bentuk laporan 


\section{HASIL DAN PEMBAHASAN}

Lokasi penelitian adalah Nagari Lambah yang merupakan bagian dari Kecamatan Ampek Angkek, Kabupaten Agam. Kecamatan Ampek Angkek berjarak $\pm 7 \mathrm{~km}$ dari pusat Kota Bukittinggi. Nagari Lambah terbagi menjadi 3 jorong, yaitu Jorong Koto Marapak, Jorong Lambah Tangah, dan Jorong Koto Hilalang. Jumlah penduduk di Nagari Lambah adalah 4.855 orang dengan jumlah kepala keluarga $1.250 \mathrm{KK}$ dan 588 PUS.

Fasilitas kesehatan yang ada di daerah tersebut adalah Puskesmas Pembantu, praktik dokter umum, Puskesmas, dan Pondok Bersalin Desa (Polindes), sedangkan tempat pelayanan KB adalah Puskesmas Pembantu, Puskesmas Biaro, dan Pondok Bersalin Desa (Polindes). Kegiatan KB dilaksanakan di bawah pengawasan IPeKB (Ikatan Penyuluh KB) Indonesia Cabang Kabupaten Agam sejak tahun 2008. Jumlah anak hidup adalah berkisar antara $2-9$ orang, dengan 4 pasang responden yang memiliki anak lebih dari 2.

Informan diambil dari 2 jorong, yaitu Jorong Koto Marapak sebanyak 5 orang dan Jorong Koto Hilalang sebanyak 5 orang. Umur informan (istri) berkisar antara 25-44 tahun dan mengaku masih haid secara teratur (di luar efek samping KB) dengan sejumlah 4 orang informan berisiko tinggi jika terjadi kehamilan. Sementara itu, umur suami adalah berkisar antara 30-52 tahun dan mengaku tinggal bersama istri setiap hari. Agama informan adalah Islam (100\%). Latar belakang pendidikan istri adalah S1 (1 orang), SMA (4 orang), SMP (2 orang), dan SD (2 orang), sedangkan latar belakang pendidikan suami adalah S1 (1 orang), SMA (4 orang), SMP (2 orang), dan SD (2 orang). Untuk pekerjaan, pekerjaan istri adalah IRT (100\%), sedangkan pekerjaan suami adalah petani (5 orang), pegawai swasta (2 orang), kontraktor (1 orang), dan buruh (1 orang).

Semua istri mengaku bahwa mereka berada dalam pernikahan pertama, sedangkan 1 dari 9 suami mengaku bahwa perkawinannya merupakan pernikahan yang kedua. Umur istri saat menikah adalah berkisar antara 19-35 tahun, sedangkan umur suami saat menikah adalah berkisar antara 21-43 tahun. Empat responden mengaku tidak pernah menggunakan $\mathrm{KB}$ dan 6 responden mengaku pernah menggunakan KB.

Tiga orang informan tokoh masyarakat berasal dari Koto Marapak dan 1 orang berasal dari Koto Hilalang. Umur Informan adalah berkisar antara 4382 tahun. Informan menganut agama Islam (100\%). Latar belakang pendidikan informan adalah beragam, yaitu 1 orang S1 PAI (Pendidikan Agama Islam), 1 orang DIII Perawat, 1 orang SMA, dan 1 orang SR (Sekolah Rakyat). Pekerjaan responden juga beragam, yaitu 1 orang PNS, 1 orang pensiun PNS, dan 2 orang IRT. Jumlah anak informan adalah berkisar 2-4 orang. Dua orang responden mengaku memiliki pengalaman pribadi dalam penggunaan $\mathrm{KB}$, sedangkan 2 orang lainnya tidak pernah menggunakan KB.

Infoman 1 merupakan seorang Alim Ulama dan juga sebagai Cadiak Pandai. Informan 2 merupakan seorang Alim Ulama dan juga Niniak Mamak. Informan 3 merupakan seorang Bundo Kanduang, Ketua PKK, dan juga kader posyandu, sedangkan informan 4 adalah seorang Bundo Kanduang, Ketua PPKBD, dan juga kader Posyandu.

Berdasarkan hasil penelitian yang telah dilakukan di Nagari Lambah, Kecamatan Ampek Angkek, Kabupaten Agam, Sumatera Barat, terdapat beberapa penyebab unmet need KB pada PUS di daerah tersebut, yaitu:

\section{a. Alasan Keyakinan Agama}

Informan kunci menjelaskan bahwa penyebab dia tetap tidak menggunakan KB adalah karena alasan agama yang melarang untuk hal tersebut. Alasan-alasan pelarangan tersebut adalah sebagai berikut: tidak mengikuti sunnah Rasul, anak merupakan rezeki dari Tuhan, memasukkan benda-benda ke tubuh adalah hal yang haram, merubah takdir dari Tuhan, dan KB hukumnya adalah haram.

\section{b. Larangan suami}


Informan kunci mengaku dilarang suami untuk menggunakan KB karena adanya pengalaman

negatif suami mengenai $\mathrm{KB}$.

“yo baa yo, ndak nio se uni doh, lagian dek suami uni ndak buliah do, soalnyo kakak ipar uni maningga dek spiral tu" (Informan kunci 4).

\section{c. Adanya keinginan terhadap jenis kelamin anak}

Informan kunci mengaku bahwa mereka belum memiliki anak perempuan, sedangkan penerus keturunan adalah anak perempuan.

"yo kecek uda ndak usah lah baKB dulu, lagian uni masih nio punyo anak padusi" (Informan kunci 5)

\section{d. Menghindari efek samping KB}

Informan kunci mengaku jera terhadap efek samping $\mathrm{KB}$ yang membuat ketidaknyamanan pada tubuh, seperti perdarahan, haid tidak teratur, seringnya sakit perut, cenderung emosional dan persepsi negatif terhadap KB. Hal ini seperti terlihat dari penuturan informan:

"yo iko, efek sampingnyo, haid ndak teratur, trus badan tu semakin bertambah berat badan, trus acok sakik2 paruik. Sudah konsul ka bidan, keceknyo ndak baa, apo karna hormon apo baa, ndak jalehlah gt" (informan kunci 6)

Nilai budaya adalah kesatuan yang kompleks, yang di dalamnya terkandung pengetahuan, kepercayaan, kesenian, moral, hukum, adat istiadat, dan kemampuan-kemampuan lain yang didapat seseorang sebagai anggota masyarakat. Untuk nilai budaya yang berkembang di dalam masyarakat dan masih ada sampai sekarang, nilai-nilai tersebut turut mempengaruhi perilaku PUS terhadap unmet need KB. Nilai-nilai yang dimaksud adalah Larangan suami, keinginan untuk memiliki jenis kelamin tertentu, dan mitos negatif tentang $\mathrm{KB}$.

Hasil penelitian ini adalah sama seperti pada penelitian Dhafer dan Asma, tentang profil unmet need KB di Kota Mosul, Iraq Utara pada tahun 2009. Penelitian ini menjelaskan bahwa penyebab unmet need $\mathrm{KB}$ ketiga terbanyak adalah karena adanya larangan dari keluarga (9.1\%). Keluarga yang dimaksud adalah ibu mertua dan suami yang mempunyai pengaruh paling besar dalam suatu keluarga (Al-Jawadi AA, Al-Bakry DH, 2010).

Penelitian yang dilakukan oleh Suseno Mutiara Rachmawati mengenai faktor yang berpengaruh terhadap kebutuhan Keluarga Berencana yang tidak terpenuhi (Unmet need for Family Planning) di Kota Kediri tahun 2011 menunjukkan bahwa terdapat faktor dominan yang berpengaruh terhadap unmet need, yaitu persetujuan suami terhadap penggunaan kontrasepsi (Suseno, MR, 2011).

Perilaku terbentuk melalui suatu proses tertentu, dan berlangsung dalam interaksi manusia dengan lingkungannya. Faktor yang memegang peranan di dalam pembentukan perilaku dapat dibedakan menjadi dua faktor, yaitu faktor internal dan eksternal. Faktor persetujuan suami merupakan salah satu faktor eksternal. Informan kunci 4 mengaku bahwa dia dilarang suami karena suami cemas dengan keadaan istri sebagaimana pengalaman yang telah lalu:

"Yo baa yo, ndak nio se uni doh, lagian dek suami uni ndak buliah do, soalnyo kakak ipar uni maningga dek spiral tu"

Penelitian serupa mengenai faktor penyebab unmet need adalah studi di Kelurahan Kayu Kubu Kecamatan Guguk Panjang Kota Bukittinggi oleh Handrina Emi pada tahun 2011. Penelitian tersebut menunjukkan bahwa suami melarang istrinya untuk memakai alat kontrasepsi karena melihat efek samping seperti terganggunya kesehatan istri setelah memakai alat kontrasepsi (Handrina, 2011).

Penulis berasumsi bahwa masih terdapat tradisi seorang istri harus patuh terhadap perintah suaminya. Hal ini berkaitan dengan sikap saling menghormati dan menghargai. Meskipun hal ini ditepis secara jelas oleh masyarakat bahwa mereka hanya bermusyawarah dengan suami terlebih dahulu dan terdapat kebebasan berpendapat yang luas di sana, secara tersirat tetap saja semua hal yang dimusyawarahkan berujung pada keputusan utama yang berada di tangan suami. Hal ini sesuai dengan penuturan informan kunci 1 dan 2: 
"Ndak usahlah awak ba kb, pandai2 awak baduo se keceknyo (suami) kan. Kan kadang tu tergantung awak baduo. Kalau wak sepakat yo ndak masalah. Bakb bana kalau tuhan ka maagiah yo tetap juo $\mathrm{ka}$ punyo anak, gt haa.." (informan kunci 1).

Penelitian ini juga menunjukkan bahwa masih rendahnya partisipasi dan kesadaran suami untuk ber-KB karena mereka merasa bahwa KB merupakan urusan rumah tangganya yang sangat pribadi, bukan masalah umum. Pertentangan dari suami ini merupakan wujud nyata dari rendahnya pengetahuan mengenai kontrasepsi, baik mengenai manfaat, kerugian, efek samping, dan komplikasinya. Dari pernyataan tersebut tersirat bahwa ketika suami memang menganjurkan untuk suatu hal, termasuk untuk tidak menggunakan $\mathrm{KB}$, istri cenderung lebih "mengalah" secara positif, maksudnya istri lebih membenarkan kata-kata suami karena adanya rasa saling menghormati dan menghargai.

Selain itu, keinginan memiliki jenis kelamin yang lain juga turut mempengaruhi unmeet need $\mathrm{KB}$. Penelitian serupa mengenai faktor penyebab unmet need adalah studi di Kelurahan kayu kubu Kecamatan Guguk Panjang Kota Bukittinggi oleh Handrina (2011) bahwa PUS masih menginginkan anak dengan jenis kelamin yang berbeda dari yang telah mereka punyai dan suami menentang istrinya untuk memakai alat kontrasepsi karena suami menginginkan anak dengan jumlah tertentu sebagai pewaris keturanan dan membantu mencari nafkah dalam keluarga (Handrina, E, 2011), sehingga hal ini turut mempengaruhi keinginan ibu dan juga suami untuk tidak menggunakan KB.

Berdasarkan penelitian yang dilakukan oleh DHS (1992-1994) di 8 negara yaitu Ghana, Madagascar, Malawi, Zambia, Indonesia, Filipina, Maroko, dan Republik Dominica, kira-kira setengah atau lebih wanita dengan unmet need yang tidak pernah menggunakan alat kontrasepsi menyatakan takut karena alasan efek samping. Ketakutan mereka jelas didasarkan pada informasi tentang pengalaman orang lain baik pengalaman yang aktual atau hanya isu (DHS dalam Suseno, MR, 2011).
Pengaruh mitos ini berawal dari pengalaman efek samping yang kemudian menyebar secara cepat dan di dalam proses penyebarannya mengalami modifikasi sesuai dengan keadaan penyebar. Jadi, pengalaman tadi berubah menjadi hal-hal yang tidak masuk akal dalam masyarakat terhadap KB.

Selain nilai budaya, penelitian ini juga menunjukkan bahwa nilai agama juga berpengaruh terhadap keputusan PUS untuk ber-KB. Nilai agama adalah fokus relasi manusia yang berkomunikasi dengan Tuhan yang digambarkan secara metaforis dan mitos. Nilai agama turut mempengaruhi perilaku PUS, dan hal ini terkait dengan norma yang bersumber dari Tuhan dan utusan-Nya. Banyak hal dikemukakan oleh responden, seperti: tidak mengikuti sunnah Rasul, anak merupakan rezeki dari Tuhan yang tidak boleh dibuang, memasukkan benda-benda ke tubuh adalah hal yang haram, merubah takdir dari Tuhan, dan KB hukumnya haram tergantung niat pengguna.

Hal yang sama juga didapatkan pada penelitian AlAkry Dhafer H. dan Al- Jawadi Asma A. tentang profil unmet need $\mathrm{KB}$ di Kota Mosul, Iraq Utara pada tahun 2009. Penelitian ini menjelaskan bahwa penyebab unmet need $\mathrm{KB}$ adalah karena adanya larangan dari keluarga $(9,1 \%)$ dan larangan agama (5,3 \%) (Al-Jawadi AA, Al Bakry DH, 2010). Penelitian yang dilakukan oleh Suseno Mutiara Rachmawati menyebutkan bahwa larangan agama merupakan salah satu alasan responden tidak menggunakan metode kontrasepsi pada kelompok unmet need (Suseno, MR, 2011).

Penelitian serupa mengenai faktor penyebab unmet need menyebutkan bahwa keputusan istri untuk tidak memakai alat kontrasepsi karena berpendapat bahwa anak yang mereka lahirkan merupakan rezeki dari Allah, sehingga tidak perlu untuk menghambat kelahiran. Memakai KB berarti menolak rezeki dari Yang Maha Kuasa, karena setiap anak mempunyai rezeki sendiri. PUS juga beranggapan bahwa anak merupakan tanggung jawab mereka sebagai orang tua, dengan arti bahwa orang lain tidak perlu 
memikirkan bagaimana mereka mencukupi kebutuhan anak-anak mereka. Hal tersebut juga merupakan pengaruh dari budaya dalam kehidupan

masyarakat (Handrina, 2011)

Informan pendukung 1, 2, 3, dan 4 menjelaskan bahwa agama tidak melarang untuk ber-KB. Akan tetapi, KB merupakan pilihan yang tepat untuk mengatur kelahiran anak pada zaman sekarang.

"kalau masalah agamo indak, kecek agamo kotilah ka baKB atau indak, manuruik budaya nyo lah turun temurun, kepercayaanyo tu nan dipakai kepercayaan urang gaeknyo dulu" (Informan pendukung 2)

"Hmm, buliah, kan ado ayat yang ngecekan sapihlah anakmu sampai berusia 2 tahun, tapi kalau dari sisi lain, memasukkan benda asing ke tubuh hukumnyo yo haram, jadi yo sampai kini awak pun masih ragu2 kan, ma lah yang batua sabananyo ko, gitu kan" (Informan pendukung 3)

"Buliah buliah.. Ndak ado larangan doh, KB ko kan lah program nasional ko" (Informan pendukung 4)

Karena Adat Minangkabau didasarkan atas kepercayaan pada agama Islam, orang Minangkabau menerima dengan tegas hukum Islam (Dewan Eksekutif Gebu Minang, 2010). Hal ini tentunya sangat berpengaruh pada pola pikir masyarakat di Nagari Lambah untuk ber-KB.

\section{KESIMPULAN}

Nilai yang berkembang dalam budaya Minangkabau mempunyai pengaruh besar terhadap unmet need KB. Adapun nilai budaya yang berkembang di dalam masyarakat dan masih ada sampai sekarang dan turut mempengaruhi perilaku PUS adalah adanya larangan suami, keinginan terhadap jenis kelamin anak tertentu, dan adanya rumor dan mitos yang negatif terhadap KB.

\section{DAFTAR PUSTAKA}

Al-Jawadi AA, Al-Bakry DH. 2010. Family Planning Unmet Need Profile in Mosul City, North of Iraq: A Cross Sectional Study. Duhok Medical Journal Volume 4, Number 1.
Abidin M. Ciri Khas Adat Budaya Minangkabau.Dipost pada 13 NOVEMBER 2013. Tersedia di http://masoedabidin.com/?p=1268

Balitbangkes (Badan Penelitian dan Pengembangan Kesehatan). 2010. Laporan Nasional Riset Kesehatan Dasar (RISKESDAS) 2010. Jakarta. Kementrian Kesehatan RI.

BKKBN. 2012. Hasil Pendataan Keluarga 2011.

BKKBN. 2013. Profil Hasil Pendataan Keluarga 2012. Jakarta.

BKKBN. 2013. Narasi Arah Kebijakan BKKBN Tahun 2010-2014. Jakarta.

Dewan Eksekutif Gebu Minang. 2010. Ajaran dan Pengamalan Adat Basandi Syarak, Syarak Basandi Kitabullah, Syarak Mangato Adat Mamakai, Alam Takambang Jadi Guru untuk Seluruh Warga Minangkabau di Ranah Minang dan di Rantau dalam Konteks Negara Kesatuan Republik Indonesia. Hasil Kongres Kebudayaan Minangkabau tahun 2010 di Bukitiinggi, Nomor: KEP 01/KKMP/6/2010. Tersedia di http://cimbuak.net/berita/114-beritakampuang-umbar/1740-kesepakatan-bersamakongres-kebudayaan-minangkabau-2010. Diakses padatanggal 17 Juni 2014.

Handrina E. 2011. Faktor Penyebab Unmet Need Studi di Kelurahan Kayu Kubu Kecamatan Guguk Panjang Kota Bukittinggi. Tesis pascasarjana Universitas Andalas. (FP2020). Washington DC.

Lee MHS, Cheng LS. Addressing the Unmet need for Family Planning among the Young People in Indonesia. Workshop on Operationalizing the Call for Elimination Of Unmet need for Family Planning in Asia and the Pacific Region. Pada tanggal 18-19 September 2012, di The Imperial Queen's Park Hotel, Bangkok. International Council on Management of Population Programmes-UNFPA.

Rahmi AS, dkk. 2013. Laporan Akhir Kuliah Kerja Nyata Pembelajaran dan Pemberdayaan Masyarakat (KKN - PPM) di Nagari Lambah Kecamatan Ampek Angkek Kabupaten Agam 
The Southeast Asian Journal of Midwifery Vol. 1, No.1, Oktober 2015, Hal: 22-28

E-ISSN: 2476-9720

P-ISSN: 2476-9738

Tahun 2013. Universitas Andalas Padang.

Suseno MR. 2011. Faktor-faktor yang Berpengaruh

Terhadap Kebutuhan Keluarga Berencana yang

Tidak Terpenuhi (Unmet Need for Family Planning) di Kota Kediri (Suatu StudiKuantitatif dan Kualitatif). Jurnal Kebidanan Panti Wilasa, Vol 2, No 1,Oktober 2011.

Winarni E, Wayhuni S. 2009. Puslitbang KB dan Kesehatan Reproduksi. Karakteristik Pus Mupar Menurut Provinsi dan Kabupaten. Badan Koordinasi Keluarga Berencana Nasional. 